\title{
CDISC Integrated Basic Data Structure Dataset
}

National Cancer Institute

\section{Source}

National Cancer Institute. CDISC Integrated Basic Data Structure Dataset. NCI

Thesaurus. Code C132357.

IBDS is the ADaM Model for the Integrated Basic Data Structure. The structure includes per pool as defined in the integrated SAP when multiple records per subject are included in integrated ADSL. (CDISC) 